\title{
Effects of D and He Implantation Depth on D Retention in Tungsten Under Simultaneous D-He Ion Irradiation
}

\author{
T.J. Finlay ${ }^{1}$, J.W. Davis ${ }^{1}$, K. Sugiyama ${ }^{2}$, V.Kh. Alimov ${ }^{3}$, A.A. Haasz ${ }^{1}$ \\ ${ }^{1}$ University of Toronto Institute for Aerospace Studies, 4925 Dufferin St., Toronto, Ontario, M3H \\ 5T6, Canada \\ ${ }^{2}$ Max-Planck-Institut für Plasmaphysik, D-85748 Garching, Germany \\ ${ }^{3}$ National Research Nuclear University MEPhI (Moscow Engineering Physics Institute), Moscow \\ 115409, Russia
}

E-mail: jwdavis@starfire.utias.utoronto.ca (James Davis)

\begin{abstract}
The effects of addition of $\sim 3 \% \mathrm{He}^{+}$in simultaneous D-He irradiation at various $\mathrm{D}$ and $\mathrm{He}$ ion energies were studied for polycrystalline $\mathrm{W}$ at 300 and $500 \mathrm{~K}$. Combinations of $250-750 \mathrm{eV} / \mathrm{D}^{+}$and $500-$ $1000 \mathrm{eV} / \mathrm{He}^{+}$were used to vary the $\mathrm{D}$ and $\mathrm{He}$ ion range relative to each other. Total $\mathrm{D}$ and $\mathrm{He}$ retention were measured by TDS up to $1473 \mathrm{~K}$, and select specimens implanted at $500 \mathrm{~K}$ were analyzed by NRA and ERD. At both 300 and $500 \mathrm{~K}, \mathrm{D}$ retention was reduced and trapping changed due to the addition of $\mathrm{He}^{+}$; however, consistent with the literature, $\mathrm{D}$ and $\mathrm{He}$ diffused well beyond the ion ranges. Furthermore, varying the ion ranges had little effect on D retention, depth profile, and trapping. D diffusion into the bulk was reduced from far beyond $7 \mu \mathrm{m}$ to less than $2 \mu \mathrm{m}$ with the addition of $\mathrm{He}^{+}$.
\end{abstract}




\section{Introduction}

Tungsten is the main candidate for the ITER divertor due to its high melting point, high thermal conductivity, and low physical sputtering. Several studies exist in the literature on the effects of helium exposure on hydrogen isotope retention in W [for example, Ref. 1 and references therein]. Ueda et al. [2] found that the relative $\mathrm{He}$ and $\mathrm{H}$ ion stopping ranges influenced the effectiveness of $\mathrm{He}$ at blocking $\mathrm{H}$ diffusion into the bulk, and hence $\mathrm{H}$ retention and blister formation. They performed experiments at $\sim 473$ $\mathrm{K}$ with 1-1.5 $\mathrm{keV} /\left(\mathrm{H}^{+}, \mathrm{H}_{2}^{+}, 50-60 \% \mathrm{H}_{3}{ }^{+}\right)$and $0.6-1.5 \mathrm{keV} / \mathrm{He}^{+}$simultaneous $\mathrm{H}-0.05 \% \mathrm{He}$ ion beams. When the $\mathrm{He}$ ion range was deeper or similar to the average $\mathrm{H}$ ion range, the $\mathrm{H}$ retention was lower than under H-only irradiation and blistering was suppressed; however, when the He ion range was shallower than the $\mathrm{H}$ ion range, there was no decrease in $\mathrm{H}$ retention or blistering [2]. However, for simultaneous D-He plasma exposures with $1-20 \% \mathrm{He}^{+}$at $\sim 573 \mathrm{~K}$ and $55 \mathrm{eV}$ /ion (i.e. D ion range being slightly deeper than $\mathrm{He}$ ion range), Miyamoto et al. [3] found that the D retention was still much lower than for the D-only case. They observed that He formed nanobubbles tens of $\mathrm{nm}$ beyond the He ion range, and hence they suggested that $\mathrm{D}$ retention is reduced when the $\mathrm{D}$ ion range is shallower than the depth of the He nanobubbles [3]. The current study investigates the effects of implantation depth at 300 and $500 \mathrm{~K}$ for simultaneous D$3 \%$ He ion beam irradiations with $5 \times 10^{23} \mathrm{D} / \mathrm{m}^{2}$ fluence by varying the $\mathrm{D}$ and $\mathrm{He}$ ion energies from 250 to $750 \mathrm{eV} / \mathrm{D}^{+}$and 500 to $1000 \mathrm{eV} / \mathrm{He}^{+}$.

\section{Experimental methods}

\subsection{Specimens}

Polycrystalline tungsten plate supplied by Plansee was cut into specimens $\sim 5.5 \times 6.5 \times 1.0 \mathrm{~mm}^{3}$ for the experiments. Grain size was measured by SEM to be 10-200 $\mu \mathrm{m}$. The specimens were mechanically polished to 1200 fine grit, annealed for 5 min, then electropolished with $1.5 \mathrm{wt} \% \mathrm{NaOH}$ solution at $3 \mathrm{~V}$ to obtain a mirror finish. Specimens were then annealed for $30 \mathrm{~min}$ to remove electropolishing residue and relieve internal stresses. Annealing was performed at $\sim 1473 \pm 100 \mathrm{~K}$, followed 
by cooling at $\sim 0.5 \mathrm{~K} / \mathrm{s}$, in the thermal desorption spectroscopy (TDS) vacuum system (see below), with a base pressure below $6.7 \times 10^{-6} \mathrm{~Pa}$.

\section{2. $D$ and He ion beam irradiations}

Irradiations were performed in the dual ion beam accelerator at UTIAS, previously described in [4]. D-only and simultaneous (SIM) D-He irradiations with $2.00-3.78 \% \mathrm{He}^{+}$were performed at 3.24$6.65 \times 10^{19} \mathrm{D} / \mathrm{m}^{2}$ flux, $\sim 5 \times 10^{23} \mathrm{D} / \mathrm{m}^{2}$ fluence, 300 and $500 \mathrm{~K} \pm 50 \mathrm{~K}, 250-750 \mathrm{eV} / \mathrm{D}^{+}$and $500-1000 \mathrm{eV} / \mathrm{He}^{+}$. These parameters were chosen to emulate as closely as possible the conditions that would occur in a tokamak with a burning plasma, within the restrictions of the $\mathrm{D}$ and He fluxes and ion energies attainable with the accelerator. Specimen chamber pressure during experiments was below $7 \times 10^{-5} \mathrm{~Pa}$. Temperature was measured for $500 \mathrm{~K}$ experiments with a type $\mathrm{K}$ thermocouple on the front of the specimen, which was clamped between a ceramic heater and the aperture plate. Implanted beam spots on the specimens were 2 mm diameter as restricted by the aperture. Independent, mass-separated $\mathrm{D}_{3}{ }^{+}$and $\mathrm{He}^{+}$ion beams with respective beam energies of 2.25-3.60 keV/ $\mathrm{D}_{3}{ }^{+}$and $1.85-2.50 \mathrm{keV} / \mathrm{He}^{+}$were used with a specimen bias of $750-1500 \mathrm{~V}$ to produce combinations of D and He ion energies. Higher D and He ion energies were not used in order to limit the amount of displacement damage induced during implantations, although this limited the implantation ranges that could be studied. Implantation ranges calculated by SRIM-2013 [5]

are shown in Figure 1. Using the mean range for each of the ion energies, He/D range ratios were calculated for each SIM D-He experiment. Range ratio > 1 indicates some He implanted deeper than D, and range ratio $<1$ indicates some D implanted deeper than He. Table 1 lists the combinations of D and He ion energies and corresponding range ratios used in the experiments. 


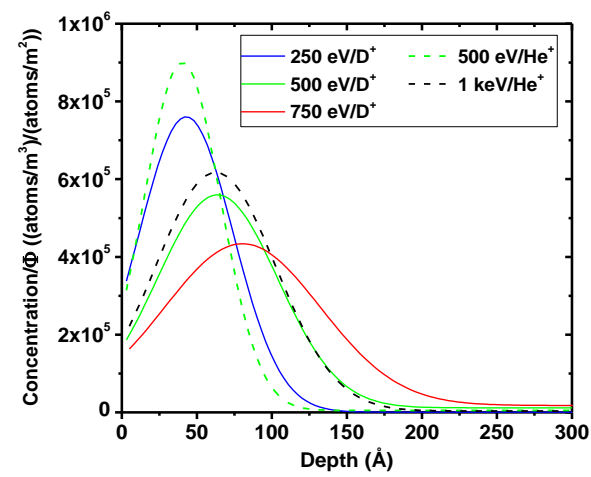

Figure 1. Implantation range profiles calculated by SRIM-2013 for ion energies used in the experiments. Calculated profiles have been fit with a Gaussian for clarity.

Table 1. Combinations of $\mathrm{D}$ and He ion energies studied in the experiments and calculated ion range ratios. A range ratio of 0 is used to denote an implantation without He (i.e. D-only).

\begin{tabular}{ccc}
$\begin{array}{c}\text { D Ion Energy } \\
\left(\mathbf{e V} / \mathbf{D}^{+}\right)\end{array}$ & $\begin{array}{c}\text { He Ion Energy } \\
\left(\mathbf{e V} / \mathbf{H e}^{+}\right)\end{array}$ & $\begin{array}{c}\text { Range Ratio } \\
(\mathbf{n m} \text { He/nm D })\end{array}$ \\
\hline 250 & -- & 0 \\
250 & 500 & 0.92 \\
250 & 1000 & 1.42 \\
\hline 500 & -- & 0 \\
500 & 500 & 0.60 \\
500 & 1000 & 0.93 \\
\hline 750 & -- & 0 \\
750 & 500 & 0.48 \\
750 & 1000 & 0.74
\end{tabular}

\subsection{Thermal desorption spectroscopy (TDS)}

After implantation, D and He retention were measured in the separate TDS system at UTIAS, previously described in [6]; with a delay of 2-15 days between implantation and TDS. Prior to TDS, the system was baked to a wall temperature of $\sim 413 \mathrm{~K}$ to desorb gases from the walls. During baking the specimen reached $\sim 333 \mathrm{~K}$, which is not high enough to release any trapped D or He. Once the chamber cooled back to room temperature, with a pressure below $6.7 \times 10^{-6} \mathrm{~Pa}$, the specimen was resistively heated 
on a strip of Rembar tungsten foil to $1473 \mathrm{~K}$ at a rate of $2-4 \mathrm{~K} / \mathrm{s}$ in order to release trapped D and He. Temperature was measured by a type $\mathrm{C}$ thermocouple spot welded to the front of the specimen. $\mathrm{H}_{2}$, HD, and mass $4\left(\mathrm{D}_{2}\right.$ plus $\left.\mathrm{He}\right)$ were measured by a Hiden quadrupole mass spectrometer $(\mathrm{QMS})$, while $\mathrm{D}_{2}$ and He were measured separately by a high resolution Extrel QMS. $\mathrm{H}_{2}, \mathrm{HD}, \mathrm{D}_{2}$, and $\mathrm{He}$ signals were calibrated using $\mathrm{H}_{2}, \mathrm{D}_{2}$, and $\mathrm{He}$ leak bottles. HD sensitivity was assumed to be the average of the $\mathrm{H}_{2}$ and $\mathrm{D}_{2}$ sensitivities.

\section{4. $D$ and He concentration depth profiling}

$\mathrm{D}$ and $\mathrm{He}$ concentration depth profiles for some specimens were measured by nuclear reaction analysis (NRA) and electron recoil detection analysis (ERD), respectively, at the Max Planck Institute for Plasma Physics in Garching, Germany, 3-4 weeks after implantation. The D concentration within the nearsurface layer (at depths up to about $0.5 \mu \mathrm{m}$ ) was measured by means of the $\mathrm{D}\left({ }^{3} \mathrm{He}, \alpha\right) \mathrm{H}$ reaction at a ${ }^{3} \mathrm{He}$ energy of $0.69 \mathrm{MeV}$ on a spot size of $1 \mathrm{~mm}^{2}$. The $\alpha$ particles were energy-analyzed with a small-angle surface barrier detector at the laboratory scattering angle of $102^{\circ}$. The $\alpha$ spectrum was transformed into a D depth profile using the program SIMNRA [7].

To determine the $\mathrm{D}$ concentration at greater depths, an analyzing beam of ${ }^{3} \mathrm{He}$ ions with energies varied from 0.69 to $4.0 \mathrm{MeV}$ was used. The protons from the $\mathrm{D}\left({ }^{3} \mathrm{He}, \mathrm{p}\right)^{4} \mathrm{He}$ nuclear reaction were counted using a wide-angle detector placed at a scattered angle of $135^{\circ}$. The D depth distribution was established by a sequence of layers with thicknesses equivalent to the depth resolution of the method ranging from $10^{17} \mathrm{~W} / \mathrm{cm}^{2}$ at the surface to $9 \times 10^{18} \mathrm{~W} / \mathrm{cm}^{2}$ at a depth of $7 \mu \mathrm{m}$ as calculated using the code RESOLNRA [8]. A concentration of deuterium as a function of depth was assumed taking into account the near-surface D concentration profile obtained from the $\alpha$ particle spectrum, and the proton counts resulting from the assumed D depth profile were calculated for the different ${ }^{3} \mathrm{He}$ ion energies. The assumed D depth profile was iteratively adjusted until the calculated proton yield curve matched the experimentally measured proton yield data set [9]. 
The He concentration profile at the near-surface layer was measured by the ERD technique using $15 \mathrm{MeV}{ }^{16} \mathrm{O}^{5+}$ as the probe beam. The incident angle of the probe beam was $75^{\circ}$ to the normal incidence, and the recoiled particles were detected by a solid state Si detector (solid angle: $0.967 \mathrm{msr}$ ) located at a scattering angle of $30^{\circ}$. The depth resolution for He under this experimental condition was calculated to be roughly $9 \mathrm{~nm}$ (by using the code RESOLNRA [8]). Each obtained ERD spectrum was analyzed by SIMNRA program [7] to determine the quantitative He concentration profile.

\section{Results and discussion}

\subsection{Total D retention by TDS}

At $300 \mathrm{~K}$, varying the range ratio from 0.48 to 1.42 does not significantly change D retention (Figure 2a). However, compared to the D-only results (shown at "0" range ratio in Figure 2a), the addition of He causes reductions in D retention. These decreases are similar for 250 and $500 \mathrm{eV} / \mathrm{D}^{+}$implantations (i.e. decreases of factor of $\sim 2$ ). Results show that there may be slight increases in D retention in 250 and $500 \mathrm{eV} / \mathrm{D}^{+}$specimens irradiated with $1 \mathrm{keV} / \mathrm{He}^{+}$, compared to $500 \mathrm{eV} / \mathrm{He}^{+}$, likely due to additional trapping caused by He-induced displacement damage. At $750 \mathrm{eV} / \mathrm{D}^{+}$, decreases in $\mathrm{D}$ retention due to the addition of He are slightly lower; perhaps due to additional trapping from displacement damage caused by knock-on effects [10].

At $500 \mathrm{~K}$ (Figure $2 \mathrm{~b}$ ), with the exception of the $500 \mathrm{eV} / \mathrm{D}^{+}$case, no clear decreasing trend in $\mathrm{D}$ retention is seen with increasing range ratio. At $250 \mathrm{eV} / \mathrm{D}^{+}$, the addition of $\mathrm{He}$ does not decrease $\mathrm{D}$ retention, while D-only D retention is quite low and comparable to SIM D-He values at 500 and 750 $\mathrm{eV} / \mathrm{D}^{+}$. Despite this, clear differences in trapping are observed between D-only and SIM D-He results at $250 \mathrm{eV} / \mathrm{D}^{+}$(see Section 3.2 below). 


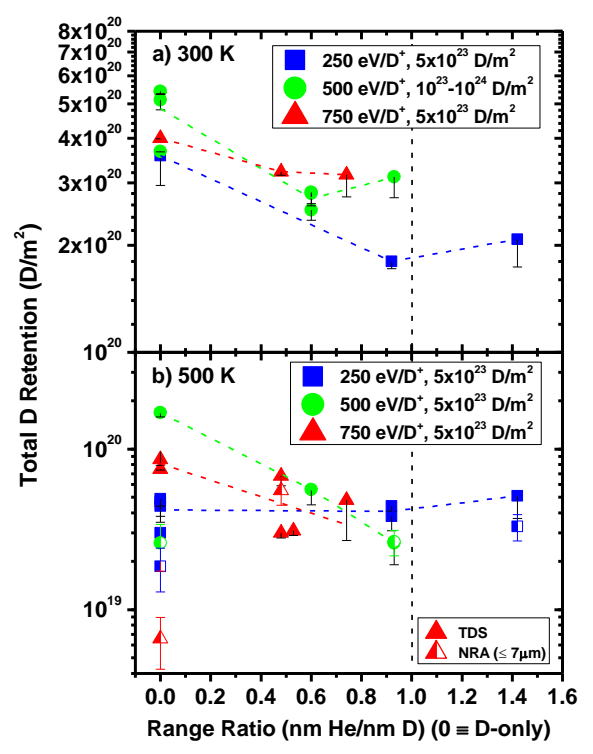

Figure 2. Total D retention vs. He/D range ratio for implantations at (a) $300 \mathrm{~K}$, (b) $500 \mathrm{~K}$. Retention values for D-only experiments are plotted at range ratio of 0 . Lines are meant as a guide to the eye only. Total D retention values calculated from NRA depth profiles are shown as half-filled symbols for comparison. The error bars on the TDS data show the HD contribution to the total D retention TDS results calculated from the quantified HD QMS signal.

At 300 and $500 \mathrm{~K}$, He retention (Figure 3) seems to be more strongly influenced by the He ion energy, than by range ratio which does not have a significant effect. He retention increases by up to $50 \%$ by increasing He energy from 500 to $1000 \mathrm{eV} / \mathrm{He}^{+}$. As well, decreasing $\mathrm{D}$ ion energy and increasing implantation temperature seem to cause slight decreases in the He retention. The exception to this is the He retention at $750 \mathrm{eV} / \mathrm{D}^{+}$and $500 \mathrm{~K}$, which is lower than at $300 \mathrm{~K}$. 


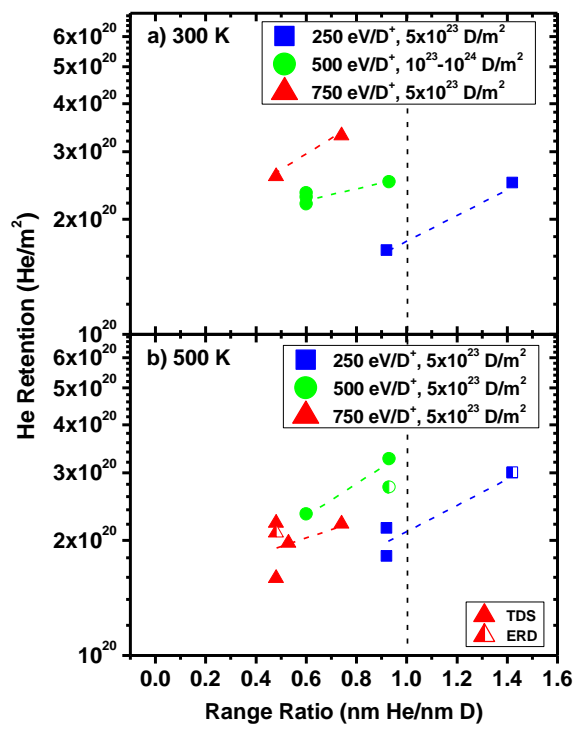

Figure 3. Total He retention vs. He/D range ratio for implantations at (a) $300 \mathrm{~K}$, (b) $500 \mathrm{~K}$. Lines are meant as a guide to the eye only. Total He retention values calculated from ERD depth profiles are shown as half-filled symbols for comparison.

\subsection{Deuterium TDS spectra}

At $300 \mathrm{~K}$, the D TDS spectra (not shown) for D-only implantations for all ion energies are largely consistent with the literature [11-13], with a main peak at $600-650 \mathrm{~K}$ and shoulder at $750 \mathrm{~K}(1.34-1.45 \mathrm{eV}$ [11-13]), and another peak/shoulder at $520 \mathrm{~K}(0.85-1.07 \mathrm{eV}$ [11,12]). Addition of He results in greater reductions in the heights of the $600-650 \mathrm{~K}$ peak and the $750 \mathrm{~K}$ peak, than reductions in the $520 \mathrm{~K}$ peak, consistent with previous results $[6,14,15]$. However, at $750 \mathrm{eV} / \mathrm{D}^{+}$, the $500 \mathrm{eV} / \mathrm{He}^{+}$spectrum is more similar to the $750 \mathrm{eV} / \mathrm{D}^{+} \mathrm{D}$-only spectrum, even though total retention is the same as at $1 \mathrm{keV} / \mathrm{He}$.

At $500 \mathrm{~K}$, the D-only TDS spectra show a main peak at 710-780 K for all D ion energies, which may be due to trapping at $1.8-2.1 \mathrm{eV}[12]$. At $500 \mathrm{eV} / \mathrm{D}^{+}$, an additional shoulder appears at $620 \mathrm{~K}$ which may be associated with $1.34-1.45 \mathrm{eV}$ trapping as seen in the $300 \mathrm{~K}$ implantations. SIM D-He implantations have a main peak at $600-650 \mathrm{~K}$, with a tail towards higher temperatures. This peak may be either also associated with the 1.34-1.45 eV traps, or it could result from D trapping with He interstitially or at dislocations around He bubbles [14,15]. Further analysis and discussion of the 300 and $500 \mathrm{~K} \mathrm{D}$ and He TDS spectra results, and depth profiling at $300 \mathrm{~K}$ will be presented in a future paper (Ref. [16]). 


\section{3. $\mathrm{D}$ and He depth profiles by NRA and ERD at $500 \mathrm{~K}$}

He depth profiles from ERD (Figure 4) show that for $500 \mathrm{~K}$ implantations at 500 and $1000 \mathrm{eV} / \mathrm{He}^{+}$, the He diffuses up to $\sim 70 \mathrm{~nm}$, with a peak concentration at 10-15 nm. This is significantly deeper than the SRIM-calculated He and D implantation ranges (Figure 1). These profiles are very similar to those found by Lee et al [15] at both 300 and $700 \mathrm{~K}$. Generally, this is consistent with the results of Miyamoto et al. [3], who also found the addition of He to be effective at reducing D retention and blistering even for range ratios $<1$. However, the ion energies used in this study are closer to those used by Ueda et al. [2], who found that blister suppression and D retention reduction only occurred for range ratios $\geq 1$, due to He trapping near the ion range. Yet, the irradiation He concentration used in the current study is much higher than that used in [2] (i.e. $3 \%$ vs. $0.05 \%$ ), and it has been shown previously that the effectiveness of He at reducing D retention and blistering is dependent upon the irradiation He concentration [3,17]. It is also evident from Figure 4 that higher He ion energy (i.e. $1 \mathrm{keV} / \mathrm{He}^{+}$) shifts the peak He concentration deeper into the specimen. The He retention calculated from the ERD concentration profiles matches the TDS data well (see Figure 3b); however, based on the TDS spectra which showed that not all the trapped He is desorbed during TDS, it is possible that a low level of He persists deeper into the specimen.

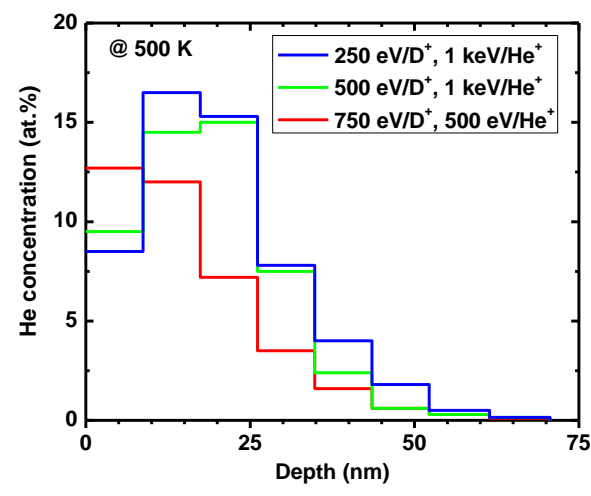

Figure 4. He concentration depth profiles for select SIM D-He implantations at $500 \mathrm{~K}$ from ERD.

Figure 5 shows the NRA D depth profiles for D-only and SIM D-He implantations at $500 \mathrm{~K}$. Interestingly, the $750 \mathrm{eV} / \mathrm{D}^{+}$case has the lowest $\mathrm{D}$ concentration in the bulk (Figure 5a) and with the addition of $\mathrm{He}$, it has the shallowest $\mathrm{D}$ concentration. Comparing the NRA D retention up to $7 \mu \mathrm{m}$ with the 
total $\mathrm{D}$ retention from TDS (Figure $2 \mathrm{~b}$ ), it was calculated that the D must extend into the bulk by at least $\sim 100 \mu \mathrm{m}$ at $750 \mathrm{eV} / \mathrm{D}^{+}, \sim 50 \mu \mathrm{m}$ at $500 \mathrm{eV} / \mathrm{D}^{+}$, and $\sim 20 \mu \mathrm{m}$ at $250 \mathrm{eV} / \mathrm{D}^{+}$. The penetration of diffusing D to depths $>25 \mu \mathrm{m}$ is consistent with previous measurements [18] which found D concentrations at the back of $25 \mu \mathrm{m}$ thick $\mathrm{W}$ foil specimens. The reason for the apparent depth scaling with $\mathrm{D}$ ion energy is currently unknown. However, differences in retention between TDS and NRA have been found in previous studies in the literature for polycrystalline W (for example, in $[18,19]$ ). It can be seen in Figure $5 \mathrm{~b}$ that for SIM D-He irradiations, D diffusion into the bulk is limited by the addition of He. Also, additional trapping occurs within the $1^{\text {st }} \mu \mathrm{m}$, up to 2 orders of magnitude above the D-only amounts. Ogorodnikova et al. [20] and Alimov et al. [17] have found similar changes in the D depth profile due to addition of $\mathrm{He}$ in plasma exposures at lower ion energy for a range of fluences and temperatures; including D depths limited to a few $\mu \mathrm{m}$, and increased D concentration in the near surface at similar D fluences [20]. However, comparison with the He depth profiles (Figure 4) shows that D diffusion must be greatly reduced, and trapping enhanced, in a region that extends $\sim 1 \mu \mathrm{m}$ deeper than the He layer detected by ERD. Perhaps the stress field [14] created by the He bubbles and He-vacancy clusters persists in this region of the lattice, far beyond the site of the peak He trapping [20]. Although He may still be trapped in this region at levels below the ERD detection limit of 0.1 at.\%, it is difficult to say whether or not this may also influence D trapping and diffusion.

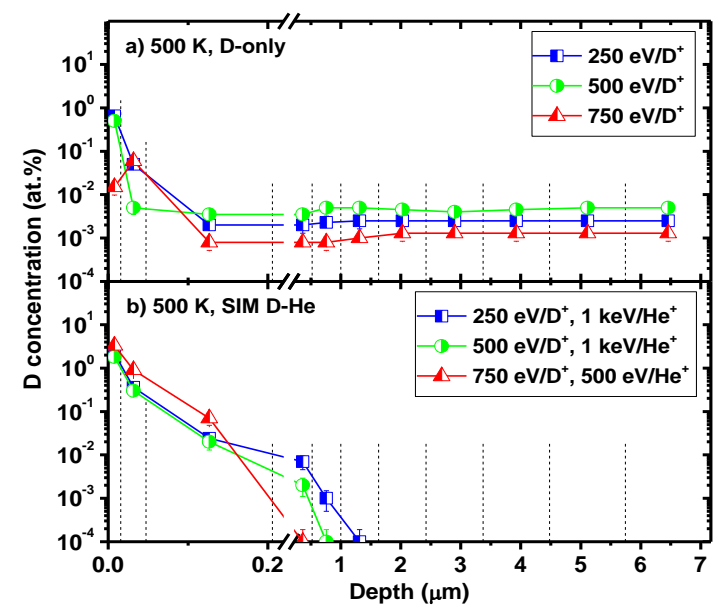


Figure 5. D concentration depth profiles for a) D-only and b) SIM D-He implantations at $500 \mathrm{~K}$ from NRA up to $7 \mu \mathrm{m}$ depth. Vertical lines show the eleven layers used for the SIMNRA calculations. For each layer, the D concentration is constant across the whole layer width.

\section{Conclusions}

At the conditions used in this study, with $250-750 \mathrm{eV} / \mathrm{D}^{+}$and $500-1000 \mathrm{eV} / \mathrm{He}^{+}$, the addition of $3 \% \mathrm{He}^{+}$reduces $\mathrm{D}$ retention at 300 and $500 \mathrm{~K}$ for all $\mathrm{He} / \mathrm{D}$ ion range ratios. He retention is affected by ion energy and temperature, but there is no strong correlation with range ratio. TDS spectra show changes in D trapping due to the addition of $\mathrm{He}$ at $300 \mathrm{~K}$ largely consistent with previous results from [14,15]. At 500 $\mathrm{K}$, there is a peak shift in the D TDS spectra due to the addition of He. However, there is little difference in the D TDS spectra for $500 \mathrm{eV} / \mathrm{He}^{+}$versus $1 \mathrm{keV} / \mathrm{He}^{+}$implantations, suggesting that range ratio does not have a significant effect on trapping at $500 \mathrm{~K}$. Consistent with the literature $[3,14,20]$, He and D depth profiles show diffusion far beyond the calculated implantation range; while for SIM D-He implantations, the presence of He greatly decreases D diffusion into the bulk.

\section{Acknowledgements}

We gratefully acknowledge the funding from the Natural Sciences and Engineering Research Council of Canada. We thank Charles Perez for his continual technical assistance with specimen preparation and in ensuring the smooth operation of the experimental facility at UTIAS. 


\section{References}

[1] M.J. Baldwin, R.P. Doerner, W.R. Wampler, et al. Nucl. Fusion 51 (2011) 103021.

[2] Y. Ueda, H. Kashiwagi, M. Fukumoto, et al., Fusion Sci. Technol. 56 (2009) 85.

[3] M. Miyamoto, D. Nishijima, Y. Ueda, et al., Nucl. Fusion 49 (2009) 065035.

[4] A.A. Haasz and J.W. Davis, Nucl. Instr. Meth. Phys. Res. B 83 (1993) 117.

[5] T.J. Finlay, J.W. Davis and A.A. Haasz, J. Nucl. Mater. 463 (2015) 997-1000.

[6] J.F. Ziegler, M.D. Ziegler and J.P. Biersack, Nucl. Instr. Meth. Phys. Res. B 268 (11-12) (2010) 1818.

[7] M. Mayer, SIMNRA User's Guide, Tech. Rep. IPP 9/113, Max-Planck-Institut für Plasmaphysik, Garching, 1997.

[8] M. Mayer, Nucl. Instr. Meth. Phys. Res. B 266 (2008) 1852.

[9] V.Kh. Alimov, M. Mayer and J. Roth, Nucl. Instr. Meth. Phys. Res. B 234 (2005) 169.

[10] M. Poon, R.G. Macaulay-Newcombe, J.W. Davis, A.A. Haasz, J. Nucl. Mater. 337-339 (2005) 629.

[11] M. Poon, A.A. Haasz and J.W. Davis, J. Nucl. Mater. 374 (2008) 390.

[12] O.V. Ogorodnikova, J. Roth and M. Mayer, J. Nucl. Mater. 313-316 (2003) 469.

[13] J.P. Roszell, PhD Thesis, University of Toronto (2012).

[14] H.T. Lee, A.A. Haasz, J.W. Davis, et al., J. Nucl. Mater. 360 (2007) 196.

[15] H.T. Lee, A.A. Haasz, J.W. Davis, et al., J. Nucl. Mater. 363-365 (2007) 898.

[16] T.J. Finlay, J.W. Davis, K. Sugiyama, V.Kh. Alimov and A.A. Haasz, (2015) to be published.

[17] V.Kh. Alimov, W.M. Shu, J. Roth, et al., Phys. Scr. T138 (2009) 014048.

[18] A.A. Haasz, J.W. Davis, M. Poon, R.G. Macaulay-Newcombe, J. Nucl. Mater. 258-263 (1998) 889.

[19] O.V. Ogorodnikova, J. Roth and M. Mayer, J. Appl. Phys. 103 (2008) 034902.

[20] O.V. Ogorodnikova, T. Schwarz-Selinger, K. Sugiyama and V.Kh. Alimov, J. Appl. Phys. 109 (2011) 013309. 